\title{
La representación del anarquismo y de la protesta social en el cine mudo argentino a través de la prensa periódica (1909-1922)
}

\author{
The representation of anarchism and social protest in the Argentine silent film \\ through the periodical press (1909-1922)
}

\author{
Lucio Mafud*
}

\begin{abstract}
Resumen: Si bien durante el período del cine mudo argentino no existió una producción cinematográfica propia del anarquismo, la problemática "ácrata" fue abordada por una serie de películas nacionales de la época. Este ciclo se inicia con las "actualidades" documentales que dieron cuenta de la Semana Roja de enero de 1909 y de las exequias del responsable de la represión, el coronel Falcón, ajusticiado por un militante anarquista. A pesar de que la cinematografía nacional alcanzó entre 1915 y 1916 un desarrollo inusitado, habrá que esperar hasta 1919 para que se exhiban nuevamente películas que traten la problemática anarquista y del movimiento obrero, ahora desde la ficción. Efectivamente, entre 1919 y 1922, el anarquismo aparece representado, salvo excepciones, desde una óptica adversa en varios films que surgen al calor de la gran cantidad de conflictos obreros que se suceden durante estos años. A través de una minuciosa búsqueda en periódicos y revistas de la época, esta investigación recupera las reseñas y publicidades de estos films lamentablemente perdidos. De esta forma, este artículo no solo permite conocer los argumentos de estos films, quienes lo dirigieron y financiaron, sino principalmente vislumbrar a través de ellos como se fue construyendo la representación del conflicto social y del anarquismo en la etapa inicial de nuestro cine.
\end{abstract}

Palabras clave: Anarquismo argentino, cine mudo argentino, movimiento obrero, Semana Trágica, huelgas patagónicas, Verano Rojo, La Huelga de las Bombas, Liga Patriótica Argentina, prensa periódica, publicaciones cinematográficas.

\begin{abstract}
During the period of silent Argentine cinema, the anarchism mouvement did not have cinematographic production. Althought the anarchist social protest was approached by a series of national films of the time. The documentary films called "actualities" gave account of the "Semana Roja" of January of 1909 and of the funeral of the person in charge of the repression, the colonel Falcón, executed by an anarchist
\end{abstract}

\footnotetext{
* Argentino, Instituto Nacional de Cine y Artes Audiovisuales (INCAA). luciomafud2@gmail.com. Este trabajo no hubiera sido posible sin el apoyo de la Biblioteca Nacional Argentina durante la gestión de Horacio González y María Pia López, a través de las becas de investigación "Oscar Landi" y "Domingo F. Sarmiento", como así tampoco sin la política de conservación realizada por el grupo de trabajo de la Biblioteca y Centro de Documentación y Archivo del Instituto Nacional de Ciencias y Artes Audiovisuales a cargo de Adrián Muoyo, y por el grupo Bael de la Federación Libertaria Argentina. Por otra parte, quiero agradecer muy especialmente a Hernán Villasenin, Constanza Gho y Lucas Domínguez Rubio, quienes aportaron sugerencias y modificaciones al texto original.
} 
militant. Although the national cinematography reached between 1915 and 1916 an unusual development, it was in 1919 when some films started to deal with the anarchism and labor movement, now from the fiction. Indeed, between 1919 and 1922, anarchism was represented in several films from an adverse perspective in the heat of the great amount of labor conflicts that occurred during these years. Through a thorough search in newspapers and magazines of the time, this research retrieves the reviews and publicity of these sadly lost films. In this way, this article allows to know the arguments of these films and who made them. But mainly this article tries to glimpse how the representation of social conflict and anarchism was built in the initial stage of our cinema.

Keywords: Argentine anarchism, silent Argentine cinema, labor mouvement, Semana trágica, Liga Patriótica Argentina, film magazines, periodical publications.

Recibido: 10 enero 2017

Aceptado: 14 marzo 2017

\section{Introducción}

La presencia del anarquismo en el campo del cine mudo coincide con su inocultable protagonismo social. En este sentido podemos trazar una cronología que se inicia en 1909 con los films $1^{\circ}$ de Mayo trágico, producido por Max Glücksmann y Las exequias del coronel Falcón y del señor Lartigau," dos "actualidades" documentales que refieren, respectivamente, a la represión contra el movimiento obrero anarquista comandada por el jefe de policía Ramón L. Falcón, y su ajusticiamiento por parte de un militante ácrata.

Estos primeros antecedentes del anarquismo en nuestro cine ${ }^{2}$ se inscriben en un contexto cinematográfico particular, dentro de un marco constante de expansión del mercado cinematográfico nacional entre 1906 y $1910^{3}$ bajo dominio del cine europeo. Ese mercado interno era abastecido desde la producción local principalmente por las

\footnotetext{
${ }^{1}$ Del impacto de ese atentado en ciertos sectores de la opinión pública da cuenta la exhibición de esta "actualidad" en forma consecutiva por un mes en diversos cines, cuando lo usual era que un documental nacional permaneciera en cartel entre uno y cinco días.

2 Tomamos como referencia el relevamiento más completo realizado hasta ahora del cine argentino entre 1896 y 1910 por Caneto [et al.], Historia de los primeros años del cine en la Argentina. 1895-1910, Buenos Aires, Fundación Cinemateca Argentina, 1996, 88 y 119.

${ }^{3}$ Mientras que en 1905 el censo de la Ciudad de Buenos Aires ni siquiera separa al cine del resto de los espectáculos (teatro, acrobacia, baile de máscaras, etc.), en 1906 ya se contabilizan 133.345 espectadores que concurren a los "biógrafos", en 1907, 666.370, en 1908, 1.870. 620, hasta llegar a 3. 469. 243 en 1910 (Ver: Anuarios estadísticos de la ciudad de Buenos Aires: 1891-1923, Buenos Aires, Dirección General de Estadísticas y Censos / Gobierno de la Ciudad Autónoma de Buenos Aires, 2010).
} 
"actualidades" documentales y, a partir de 1909, por la naciente ficción histórica ${ }^{4}$ que surge en el contexto político de los preparativos de los festejos del Primer Centenario de la Revolución de Mayo. El conjunto de ese cine, tanto documental como de ficción, refuerza la construcción de una Argentina ideal desde la perspectiva de la elite y de los grupos de poder dominantes, ya sea en la construcción del relato histórico escolar, o bien en una visión de la Nación signada por actos del poder ejecutivo, desfiles y maniobras militares, ceremonias, diversiones y funerales del patriciado. Es precisamente ese discurso hegemónico, reiterativo y monótono, de las "actualidades" documentales, que termina por construir la idea de una Nación cristalizada y armónica, el que es puesto en cuestión indirectamente por el accionar del anarquismo en el campo político. La conflictividad social implícita en los documentales referidos al $1^{\circ}$ de Mayo de 1909 o al ajusticiamiento de Falcón, si bien puede ser cuestionada por el discurso cinematógrafo oficial, de ninguna manera puede ocultar la presencia de una tensión, de una "amenaza" que acecha al orden establecido. Más aún cuando estas actualidades, que se apartan de la representación festiva y pintoresca de la Nación característica del género, se estrenan en salas aristocráticas como el Teatro Ateneo y en el contexto de exaltación patriótica propia del Primer Centenario.

En los años siguientes, no aparecen referencias al anarquismo en el cine argentino hasta que los diversos conflictos sociales entre 1918 y 1922 impidieron que siga permaneciendo fuera de campo. En efecto, la presencia del anarquismo y del movimiento obrero antes y durante de la Semana Trágica de enero de 1919 y, a comienzos de la década de 1920, las huelgas en el sur de la provincia de Buenos Aires, en la Patagonia y en el norte (la Forestal) va a tener un correlato cinematográfico. Es precisamente en esas fechas donde se producen una serie de documentales (La semana trágica en Buenos Aires, Alma argentina) y obras de ficción (Juan Sin Ropa, Luchas en la vida, El triunfo de la verdad, Allá en el Sur..., ¡Patagonia! y La ley del hombre ${ }^{5}$ que abordan la problemática del anarquismo y la luchas sociales de la época; en la mayoría de los casos, desde una perspectiva ideológica antagónica.

Estos films, además, se inscriben en un contexto muy específico dentro de la producción cinematográfica local. Desde 1914, el cine nacional, debido a la limitación de la importación de films extranjeros durante la Primera Guerra Mundial ${ }^{6}$ y a la acelerada expansión del consumo cinematográfico en Argentina, ${ }^{7}$ había encontrado la posibilidad de

\footnotetext{
${ }^{4}$ Esta tendencia se inicia en 1909 con La Revolución de Mayo y continua al año siguiente con La batalla de San Lorenzo, Paso de los Andes, Invasiones inglesas, Güemes y sus gauchos, Camila O’ Gorman, Amalia, Facundo Quiroga y El fusilamiento de Dorrego, entre otras.

${ }^{5}$ Con anterioridad, esa visibilidad cinematográfica se expresó en Carlitos de Buenos Aires y la huelga de los barrenderos (1916, [Cunill?]), a través de las travesuras de un Carlitos Chaplin argentino durante un reclamo sindical apoyado, entre otras tendencias, por la F.O.R.A. V anarquista que había paralizado la recolección de basura en la ciudad de Buenos Aires.

${ }^{6}$ Por ejemplo, mientras que en 1911 ingresaron desde Europa 1.600 .000 metros de película, en 1913 la cifra alcanzó los 3.600.000 (Acosta, 1918). Si bien para 1914, se proyectaba la importación de una cantidad mayor, la irrupción del conflicto bélico a mediados de ese año redujo las expectativas a 3.000.000 metros (Acosta, 1918). De esta manera, existía una demanda interna que de alguna forma necesitaba ser colmada y que la importación no llegaba a satisfacer.

${ }^{7}$ La expansión era tal que para ese entonces el cine ocupaba el primer lugar en el ocio cultural de la época. Según estadísticas de la ciudad de Buenos Aires, mientras que en 1911 las cifras de concurrentes a
} 
un desarrollo inusitado que parecía confirmarse con el éxito económico de films nacionales como Amalia (1914) y Nobleza gaucha (1915). Es en ese contexto que se constituyen un conjunto de productoras, muchas de ellas conformadas por distribuidores y exhibidores nacionales, pero también por personalidades ajenas al gremio cinematográfico atraídas por las posibilidades del incipiente negocio. Así, diversas compañías teatrales, dramaturgos y escritores de folletines, pasan a ocupar el rol de intérpretes, guionistas y directores cinematográficos. Si bien para el periodo 1918-1922 esas expectativas habían empezado a decaer por múltiples factores, entre ellos, el dominio del mercado interno por parte del cine estadounidense, todavía persistían en el intento de producir películas nacionales empresarios teatrales y distribuidores como Héctor Quiroga (Juan Sin Ropa), interpretes aficionados de una academia cinematográfica (Luchas en la vida), documentalistas como Federico Valle o Pío Quadro, y agrupaciones políticas como la Liga Patriótica Argentina, entre otros.

Hay que señalar en este punto que el estudio del cine del período se torna problemático debido a la pérdida de la casi totalidad de las obras, por lo que debemos depender de fuentes indirectas (críticas, crónicas del filmación y otros documentos). Para esta investigación hemos consultados tres tipos de fuentes. En primer lugar, los primeros semanarios especializados, destinados a exhibidores y distribuidores, como Excelsior y La Película, que surgen en 1914 y 1916, respectivamente. Estas revistas que comienzan a editarse en un contexto de continua expansión del consumo cinematográfico en Argentina representan los intereses contrapuestos de empresas distribuidoras en pugna por la hegemonía del mercado interno. En sus páginas podemos encontrar datos sobre el rodaje, críticas, y publicidades de las películas nacionales como así también información sobre la exhibición y distribución de la producción extranjera en nuestro país. Luego relevamos las revistas destinadas al espectador en general, como Imparcial Film (Buenos Aires, 19181932) y Cine Universal (Buenos Aires, 1919-1921). Finalmente, también revisamos los diarios de la época y diversas revistas culturales citadas en la bibliografía. Del entrecruzamiento de estas fuentes hemos logrado reconstruir, en primer lugar, las fichas técnicas más completas de los films citados y, en segundo lugar, las descripciones de los argumentos y otros detalles de producción. Este trabajo, que nunca había sido emprendido en profundidad hasta el momento en Argentina, permitió la construcción de un corpus de información que hemos utilizado como base de nuestro análisis.

De todos modos, la escasez de datos disponibles hace que nuestra reconstrucción sea, en parte, conjetural. ${ }^{8}$

representaciones teatrales (6.128.898 asistentes) eran superiores a las de exhibiciones cinematográficas (4.650.653 asistentes), a partir de 1912 esa proporción se invirtió: 7.090.110 personas asistieron a funciones de cine, y alrededor de 5.163.480 a las teatrales. En 1914 esa brecha se acentuó, ya que 12.138.529 espectadores concurrieron a los "biógrafos", y aproximadamente 3.082.357 a los teatros (Ver: Anuarios estadísticos de la ciudad de Buenos Aires: 1891-1923, Buenos Aires, Dirección General de Estadísticas y Censos / Gobierno de la Ciudad Autónoma de Buenos Aires, 2010).

${ }^{8}$ Para una ampliación sobre la producción, distribución y conservación del cine mudo argentino de esos años ver: "Introducción" y "Panorama del cine mudo argentino (1914-1923)", en Mafud, Lucio, La imagen ausente: El cine mudo en publicaciones gráficas. Catálogo. El cine de ficción (1914-1923), Buenos Aires, Biblioteca Nacional /Teseo, 2016. 


\section{La Semana Trágica}

Pocos datos tenemos, por ejemplo, de la "película de actualidad" La Semana Trágica en Buenos Aires filmada por el cameraman Pío Quadro durante los sucesos de enero de 1919. Si bien resulta difícil establecer la posición ideológica que adopta este documental sobre dichos acontecimientos, las palabras de un comentarista cinematográfico señalando que "los últimos días pasados por la población de Buenos Aires, bajo el temor de lo desconocido y los desmanes de la turba han sido tomados en su puntos más culminantes, con visible peligro del operador [...] perdiendo en la cuestión un trípode y salvando a la película con gran trabajo" "parecen dar cuenta de que se trataba de un film con una mirada antagónica al movimiento huelguista en la medida que la violencia de la muchedumbre, al cernirse no solo sobre el operador o poner en juego la estabilidad de la cámara, recae en última instancia sobre el espectador mismo, ya que es ese el punto de vista con el cual se identificará durante la proyección. Esa marca de violencia se aborda explícitamente en el sumario del film, con la mención al "incendio del asilo y templo de Jesús Sacramentado", 10 que por su componente anticlerical posiblemente es atribuido a tendencias políticas radicalizadas como el anarquismo o el sindicalismo revolucionario.

Si bien una publicidad menciona "el entierro de las primeras víctimas" (en general obreras) y luego las "cargas de caballería"; sin embargo, al indicar que "se reproducen los momentos más angustiosos de la última huelga sangrienta", 11 es probable que el film termine por establecer una asociación intrínseca entre huelga y violencia, y coloque el reclamo obrero como principal responsable de la misma.

Esta hipótesis tiende a corroborarse con la participación de su realizador Pío Quadro como cameraman de Alma argentina o El despertar de una raza (1919, Luis Ramassotto), la primera película de propaganda patrocinada ${ }^{12}$ (y probablemente financiada en su totalidad) por la Liga Patriótica Argentina, la agrupación que formaron los comandos civiles que participaron en la represión contra los huelguistas.

Este film, un documental con segmentos de ficción, reproduce la marcha convocada por la Liga Patriótica el 24 de mayo de 1919 en repudio a los sucesos de la Semana Trágica y diversas manifestaciones patrióticas en torno a la conmemoración de la Revolución de Mayo.

Ya desde el título, el film presentará una continuidad entre nación, espíritu y raza, que intentará conjurar a su contrario, extranjero y ateo. Frente al caos de la huelga, el orden del desfile en el que participan "200.000 almas"; frente al ateísmo desintegrador, la inclusión del tedeum y de las fiestas parroquiales.

Es que la manifestación está organizada según el modelo del desfile militar que, al mismo tiempo, dibuja un recorrido histórico de la Nación Argentina desde una perspectiva

\footnotetext{
${ }^{9}$ Imparcial Film 10, 5/2/19, 4.

${ }^{10}$ Publicidad en Imparcial Film 10, 5/2/19.

${ }^{11}$ Idem. Subrayado nuestro.

12 Así se afirma en Excelsior 277, 2/7/19, 775. A su vez La Película (142 12/6/19, 21) da a entender algo similar al indicar que la exaltación patriótica del film tenía como propósito "que cayera en gracia de los jóvenes guardias blancas”, denominación de los comandos civiles que constituyeron la Liga Patriótica.
} 
liberal conservadora, que coincide con los textos doctrinarios de la Liga. Así, por ejemplo, desfilan el "glorioso e histórico regimiento de granaderos a caballo" de San Martín, "los guerreros del Paraguay" y "los expedicionarios del desierto" junto con sectores de la policía, el ejército y las columnas civiles de la Liga. Es decir, la narrativa del desfile establece una línea que va desde la Independencia hasta la conquista del territorio de las comunidades nativas por parte del roquismo pasando por la Guerra de la Triple Alianza, para confluir en un glorioso presente donde los nuevos "guardianes de la nación" parecen tomar la posta de los antiguos.

Este film forma parte de las actividades culturales que fomentaba la Liga Patriótica en todo el país, que consistían en la organización de celebraciones de fechas patrias, en intensificar la educación nacionalista y en "la divulgación del conocimiento de nuestra historia por medio de conferencias, publicaciones o cualquier forma de propaganda, especialmente la de libros infantiles". 13 De ahí la inclusión dentro de este film "instructivo" de una imagen que representa el ideal de una niñez educada para esta agrupación: un desfile escolar de "150.000 niños" ante la Casa de Gobierno cantando el himno nacional; precisamente en un contexto caracterizado por un alto componente inmigratorio europeo, y la llamativa participación de niños, durante los hechos de la Semana Trágica. ${ }^{14}$

El despertar de una raza se produce como "protesta a los actos vandálicos de los bolshevikis y en desagravio al Pabellón Nacional"15 durante enero de 1919, en reacción a un otro definido por un término que conjuga al mismo tiempo la amenaza del caos revolucionario y su carácter extranjero. Bajo ese término, cuya grafía acentuaba el carácter extraño al idioma nacional, la Liga Patriótica, como era común en la época, englobaba a las tendencias de la izquierda radical que por ese entonces simpatizaban con la revolución rusa, como el anarquismo ${ }^{16}$ o el sindicalismo revolucionario, entre otros. ${ }^{17}$ Sin embargo, esta organización establecía una teoría conspirativa alrededor de estos actos: un plan orquestado por los "maximalistas rusos" y los "malos" extranjeros con la intención de instaurar la dictadura de los soviets tanto en Argentina como en Uruguay. ${ }^{18}$ Desde esta perspectiva

13 "Enunciación de propósitos", La Nación, 31/3/19.

${ }^{14}$ Al respecto, por ejemplo, Estanislao Zeballos, político conservador y miembro de la junta de la Liga Patriótica, evidenciaba su preocupación por "la acción tumultuaria de grupos implacables, formados en su mayoría por extranjeros y por mayor número de niños de 10 a 15 años". Y señalaba que "la mayor parte de estos niños han concurrido y concurren a las escuelas del Estado y el hecho comprueba una vez más el fracaso de nuestro sistema de educación" Godio, Julio, La Semana Trágica de enero de 1919, Buenos Aires, Granica editor, 1972, 148 y 151.

${ }^{15}$ Publicidad La Película 142, 12/6/19, 18.

${ }^{16}$ Como sostiene Doeswijk, el anarquismo argentino apoyó de diversas formas la revolución rusa por lo menos hasta 1921, año en que el grupo de La Protesta y la FORAC (antes FORA del V Congreso) expulsa a la fracción anarco-bolchevique. La excepción la constituye el grupo de La Obra que comienza a cuestionar ese proceso revolucionario ya a partir de mayo de 1919. Ver: Doeswijk, Andreas, Los anarco-bolcheviques rioplatenses (1917-1930), Buenos Aires, CeDInCI, 2013.

${ }^{17}$ Un comentario publicado en La Película $142(12 / 6 / 19,21)$ confirma que esta obra tiene "el encargo de hablar mal de los anarquistas y demás exaltados".

${ }^{18}$ Según Lvovich, durante el transcurso de la Semana Trágica, las autoridades uruguayas anunciaron que habían comprobado la supuesta existencia de tres soviets en Montevideo y procedieron a la persecución de militantes obreros y de inmigrantes de origen ruso y judío. Probablemente por esta razón, en los textos promocionales de la película se subraya la presencia de la delegación uruguaya. Lvovich, Daniel, "La Semana 
conservadora, estas ideologías ajenas al ser nacional son manifestaciones de la barbarie - de ahí la referencia a los "actos vandálicos"- que acecha a la nación civilizada, ${ }^{19}$ una suerte de actualización del malón o del caudillo Solano López. Como reacción a esa amenaza, la manifestación patriótica pone en escena la conjunción de los sectores que el anarquismo busca destruir a través de su prédica antimilitarista, anticlerical y antiestatista, y que para el film conforman, más allá de las divergencias internas, un bloque compacto, sin fisuras, que representa a la Nación Argentina: el Estado representado por el poder ejecutivo a cargo del presidente Yrigoyen y sus ministros, y por sus fuerzas represivas: el ejército y la policía, en conjunción con las columnas de la Liga, bendecidas por la Iglesia Católica. Una barbarie, una invasión de lo foráneo, que debe ser combatida en todos los frentes, tanto con las armas, como a través de la instrucción y la propaganda nacionalista; es decir, con el cine mismo.

Ese mismo año se estrenan dos películas de ficción: Juan Sin Ropa, dirigida por el cineasta francés Georges Benoît, y Luchas en la vida (probablemente dirigida por Emilia Saleny), producida e interpretada por alumnos de la academia cinematográfica "Saleny", que dan la impresión de aludir al anarquismo en un contexto de radicalización obrera alrededor de los sucesos de enero de 1919.

Luchas en la vida narra la historia de un obrero y su hija que arriban a la Argentina desde Europa en busca de un sobrino, luego de que el jefe de la familia quedara ciego y viudo como consecuencia del atentado de un "pacifista" que intentó volar la fábrica de explosivos donde trabajaba. Es muy posible que el argumento de este film, también lamentablemente perdido, hiciera referencia a través del personaje del "pacifista" que comete un atentado con explosivos, a métodos de propaganda por el hecho característicos de ciertos militantes anarquistas, cuyo caso emblemático en Argentina es Simón Radowitzky, un partidario de la no violencia que decide atentar con una bomba contra el comisario Falcón, responsable del asesinato de obreros anarquistas durante el $1^{\circ}$ de mayo de 1909.

En las fuentes que pudimos recuperar ${ }^{20}$ se vislumbra una dicotomía entre el "viejo mundo" signado la pérdida de la familia y la violencia (ya sea la ejercida por el supuesto

\footnotetext{
Trágica en clave transnacional. Influencias, repercusiones y circulaciones entre Argentina, Brasil, Chile y Uruguay (1918-1919)", en Circule por la derecha: percepciones, redes y contactos entre las derechas sudamericanas, 1917-1973, Los Polvorines, Universidad Nacional de General Sarmiento, 2016.

${ }^{19}$ El líder de la Liga, Manuel Carlés, da cuenta de esta dicotomía en el siguiente párrafo: "El desborde de la osadía [la rebelión obrera de 1919] sólo pudo compararse con la desidia de la gente que hubiese perdido todo con la derrota de la civilización, triunfando la barbarie de los antisociales" ("Reunión de propagandistas", $L a$ Nación, 31/3/20).

${ }^{20}$ Por ejemplo, la siguiente sinopsis: "Pedro [Nerval] es un obrero que trabaja y vive modestamente con su mujer. Cierto día, hallándose en la fábrica de explosivos donde trabaja, sorprende a un pacifista que hace volar la fábrica y en la lucha sufre las consecuencias de la explosión perdiendo la vista. Su mujer, aterrada por ese hecho, fallece dejando al obrero con su hija Nelda, quien sirve de lazarillo al pobre ciego. En busca de un sobrino, padre e hija emprenden viaje a América. Jack, que es el sobrino a quien buscan, ha sido víctima de las redes de un aventurero, cuyo ascendiente sobre él llega a hacer que vaya a robar. Después de interesantes escenas, Pedro, el ciego, consigue recuperar la vista mediante una operación delicada. Al volver sus ojos hacia el cirujano que lo ha curado, reconoce en él al pacifista a quien debe sus desgracias, pero en un impulso generoso lo perdona" (Imparcial Film 39, 15/12/20, 4).
} 
anarquista, o la que se infiere de la fabricación de explosivos en el contexto de una Europa desangrada por la Primera Guerra Mundial), ${ }^{21}$ y una Argentina caracterizada por la posibilidad de reconstruir el núcleo familiar y el milagro de la sanación: la recuperación de la visión por medio de una intervención quirúrgica. Un "nuevo mundo" que, aunque presenta sus peligros, está caracterizado por la esperanza, la redención y la cicatrización de las viejas heridas, lo que se refleja en la conversión del antiguo "terrorista" en el respetable cirujano que cura la ceguera del protagonista.

De esta manera, el conflicto social está asociado a otro contexto, la vieja Europa, y de alguna forma su superación está dada por una suerte de redención y ascensión social propia del nuevo mundo a través de una profesión humanista, pero también utilitaria y respetable como la medicina. En cierto sentido, el film parece traslucir la visión ideológica de sectores inmigratorios que alcanzaron cierto status social medio, de ahí la importancia temática de la familia, la ascensión social por medio de la educación y la superación de ideologías cuestionadoras del orden burgués, precisamente en un contexto de conflictividad social donde esas ideologías vuelven a adquirir protagonismo en estas "tierras de paz".

Probablemente Juan Sin Ropa (1919, Georges Benoît) sea el film del período que más haya sido vinculado al anarquismo y a las luchas obreras de la época, ${ }^{22}$ quizás por la relación entre su guionista, el poeta y dramaturgo José González Castillo, con el ideario ácrata. El film, del que se conservan solo los primeros veinticinco minutos sin intertítulos, ${ }^{23}$ alude al recrudecimiento del conflicto social de la época ${ }^{24}$ a partir del montaje alterno que permite establecer una serie de oposiciones generales -pobres/ricos,

\footnotetext{
${ }^{21}$ Ya en el film El pañuelo de Clarita, dirigida en 1919 por Emilia Saleny e interpretada por gran parte del elenco de Luchas en la vida, había un cuestionamiento a la guerra que había desangrado a Europa hasta el año anterior.

${ }^{22}$ Ver, por ejemplo: Di Núbila, Domingo, La época de oro del cine argentino, Buenos Aires, Ediciones del Jilguero, 1998, 24-26; Bernini, Emilio, "Escenas callejeras. La ciudad en el cine argentino 1919-1943", El Matadero 2, Buenos Aires, Facultad de Filosofía y Letras, 2000; Oger, Adriana y Daniel de Lucia, “¡Ni dios, ni amo, ni taquilla! El anarquismo en el cine argentino", Pacarina del Sur 11, abril-junio, 2012.

23 Esta es una de las sinopsis que permite vislumbrar la estructura completa de la película: "El tipo clásicamente denominado en un poema célebre, de donde es aquel verso: ‘Juan Sin Ropa' se llamaba, es en el film un tal Ponce, mozo campesino que encuentra ocupación en un frigorífico, progresa en su oficio y llega a ser 'leader' de los obreros, participando activamente en un movimiento huelguístico, como aquellos de que fuera recientemente teatro Buenos Aires. Peligrosamente comprometido, se salva, trepando en el auto, a toda carrera, que conduce a una joven, precisamente a la hija del dueño del frigorífico que descubre aptitudes en él, y adivina que puede ser un hombre útil. Decidido a luchar en otra forma, Ponce regresa a la campaña, entrégase a las faenas agrícolas y se convierte en un colono de prestigio; entonces se le presenta la oportunidad de combatir a los 'agiotistas', que lucran con el comercio de cereales, elevando desmesuradamente los precios. La joven aquella que causó impresión en el mozo, se ha casado con un cerealista, hacendado autoritario y despótico que convierte para su esposa en un calvario el matrimonio. Habrá de luchar en contra de este, defendiendo a los colonos explotados, y, aun en contra del politiquero de la región. Y, por fin, evitará si no la muerte por asesinato de su enemigo, el despojo estimulado por el hermano de su protectora, llevado a la práctica en complicidad con dos rateros. Viuda la joven, 'Juan Sin Ropa' podrá realizar su anhelo de dicha, el mismo de la dama como justo premio a su voluntad y honradez" (La Mañana, $8 / 1 / 19,12)$.

${ }^{24}$ Hay que tener en cuenta, como señala el investigador Héctor Kohen $(2005,45)$, que el film, estrenado luego de los sucesos de la Semana Trágica, fue realizado el año anterior.
} 
campo/ciudad- pero que también se traduce dentro de cada uno de los términos; por ejemplo, entre la hija del patrón, caritativa con los pobres, y su marido, despótico e insensible con los obreros. En el mismo sentido, el sector proletario está representado por el personaje principal del film, Juan Ponce, un obrero "bien intencionado", preocupado por las demandas de su clase pero conciliador con los patrones, y El Clinudo, un líder sindical proclive a la violencia, cuyo apodo, que remite a lo desarreglado y lo sucio, da cuenta de una interioridad negativa. Podemos inferir que este personaje, debido a su postura de confrontación con el sector capitalista en el espectro sindical, representaría la tendencia más radicalizada dentro del movimiento obrero.

Juan Sin Ropa propone la superación del conflicto entre el capital y el trabajo por medio de la conciliación de clases, expresada en el amor entre la "niña bien", sensible al sufrimiento de los pobres, y el antiguo proletario Juan Ponce, que se transforma progresivamente en un hombre pudiente gracias al sentido de superación inculcado por su joven esposa. Por lo tanto, el film expresa una tendencia reformista que cuestiona todo "extremismo", ya sea el de los insensibles patrones o el de los violentos dirigentes sindicales, y exalta, como señala Héctor Kohen ${ }^{25}$, la reivindicación del trabajo como forma de ascenso social. De esta forma, Juan Sin Ropa puede tornarse representativo de amplias tendencias políticas - de ahí una de las claves de su éxito-, desde el radicalismo yrigoyenista, el partido socialista y el sindicalismo reformista, hasta la preocupación social de la iglesia católica contenida en la encíclica Rerum novarum, e incluso algunos sectores de la Liga Patriótica. ${ }^{26}$

\section{Entre el "Verano Rojo" y "La Huelga de las Bombas"}

Entre diciembre de 1919 y enero de 1920, se produce el denominado "Verano Rojo", que se inicia con una importante huelga de trabajadores rurales en el sur de la Provincia de Buenos Aires en reclamo de mejoras laborales, llevada a cabo por la Unión de Trabajadores Agrícolas, dependiente de la F.O.R.A. anarquista. ${ }^{27}$ En ese contexto circulan diversos panfletos firmados por la Agrupación Revolucionaria de la Región Argentina, en realidad expresión de grupos anarco bolcheviques, exigiendo la liberación de los presos políticos bajo amenaza de la destrucción de las cosechas y de maquinarias agrícolas si dicha

\footnotetext{
${ }^{25}$ Kohen, Héctor, “Algunas bodas y muchos funerales", Cuadernos de Cine 5, Buenos Aires, 2005, 45.

${ }^{26}$ Por ejemplo, en diversos textos de esta organización se promueve la armonía entre el capital y el trabajo y el mejoramiento de las condiciones de los obreros, en un contexto de temor a la revolución social luego de los sucesos de la Semana Trágica.

${ }^{27}$ En su trabajo ya citado, Doeswijk se refiere al período 1918 -1921 como el "trienio rojo argentino". Efectivamente, numerosos conflictos obreros se suceden durante esos años: las huelgas rosarinas y porteñas de los policías agremiados, la Semana Trágica, las huelgas en La Forestal, el llamado "Verano Rojo", la huelga de los maestros de Mendoza, la huelga de los marítimos, la Huelga de las Bombas y los reclamos de los peones de Santa Cruz en 1921. Hasta ahora la bibliografía al respecto está compuesta por: Godio, Ibid.; Bilsky, E., La Semana Trágica. Buenos Aires, CEAL, 1984; Jasinski, A., Revuelta obrera y masacre en La Forestal, Buenos Aires, Biblos, 2013; Bayer, O., La Patagonia rebelde, Buenos Aires, Planeta, 2002; Ascolani, A., "Una ciudadanía restringida, tensiones en torno a los derechos y las obligaciones del magisterio. La gran huelga de 1921, Santa Fe, Argentina", Educação em foco 15, 2011; a lo que se suma el reciente trabajo de Roberto Pittaluga, Soviets en Buenos Aires, Buenos Aires, Prometeo, 2015.
} 
demanda no fuese cumplida. La prensa burguesa dio entonces cuenta, desde una perspectiva sensacionalista, de un "plan sedicioso anarco agrario" que desencadenó una política represiva por parte del Estado y de grupos civiles.

Por otro lado, en marzo de 1920 se produce un reclamo sindical policial en la Capital Federal apoyado también por la FORA del V Congreso y por el grupo anarcobolchevique de Bandera Roja, que derivó en una huelga policial. Los anarquistas pretendieron sumar otro reclamo por la liberación de los presos políticos, muchos de ellos en situación de ser deportados. Sin embargo, la institución policial hizo fracasar esta tentativa a través de la ocupación de comisarías, detenciones y despidos, como así también con allanamientos, previa infiltración, de locales ácratas y diversos lugares del conurbano bonaerense donde se requisó gran cantidad de explosivos en poder de los anarquistas. Nuevamente la prensa sensacionalista de la época, le dio una amplia cobertura a "La Huelga de las Bombas", dando cuenta de otro plan terrorista. ${ }^{28}$

El triunfo de la verdad (1921, Perry) parece aludir a estos hechos de manera más o menos explícita. Porque en el film parecen sobreimprimirse dos historias. La primera, un melodrama que sigue más o menos fielmente la novela homónima de Juan B. Lecouna, en la que no hay ninguna referencia al anarquismo ni a los movimientos sociales de la época. La segunda cuenta una trama paranoica donde un anarquismo, pródigo en bombas y conspiraciones, se infiltra, desde el extranjero, en la ciudad y luego avanza hacia el campo.

La película comienza cuando un deportado ruso de tendencia anarquista logra reingresar al país con el pasaporte de un joven estadounidense que viene a la Argentina a probar fortuna. Una vez en el país intenta convencer a sus antiguos compañeros de armas a "levantar al obrero del campo" y realizar atentados con bombas ${ }^{29}$. La modalidad de acción

\footnotetext{
${ }^{28}$ Para un estudio detallado de estos hechos, ver Doeswijk, Ibid., 124-154.

${ }^{29}$ Una de las sinopsis del film: "Un joven ruso deportado consigue introducirse al país con un pasaporte que ha sustraído a un joven yanqui, que viene a probar fortuna, sin ninguna condición y carente de experiencia para luchar por la vida. Ya en Buenos Aires los dos, el primero se une a un antiguo compañero anarquista, Duval, que vive con Sonia, la hermana del deportado, y Lake, el yanqui busca trabajo en una estancia. El hermano de Sonia ignora las relaciones de esta con Duval y que este ha cambiado de posición y de ideas. Ahora es propietario, detesta a los anarquistas, Sonia que ama a Duval, no profesa ya ideas avanzadas. Solo, sin apoyo de Duval, el deportado trata por medios violentos de convertir de nuevo a la anarquía a su ex compañero, incitándolo a cooperar en su obra de 'levantar' al obrero del campo. Duval se resiste [...] Carlos Duval, que se ha tornado un vicioso de la ciudad, pretende traer del campo a Margarita, flor delicada, espíritu soñador, que vive embriagada en la dulce esperanza del príncipe alado. Casimiro, un muchacho de la estancia, ama a Margarita, pero frente a este rival teme por su suerte. Incitada por las falsas promesas de Duval, un día Margarita huye de su casa y va a la de Duval en busca de apoyo para hacerse bailarina. Sonia que siente unos celos profundos, es la que cuida de la virtud de su huésped, más por egoísmo que como deber. Un día de comida en casa de Duval, este pretende violentar a Margarita, quien defendida por Sonia, huye y debuta en un teatro consagrándose una eximia danzarina. Volvamos ahora al campo. La madre de Margarita pide a Lake [que] le busque su hija, este se va a la ciudad y agota todos sus recursos sin lograr sus propósitos, hasta que obligado por la circunstancia se mete de chauffeur de un taxi y se le presenta la oportunidad de descubrir al deportado en un rincón de la provincia de Buenos Aires, escondido en los sótanos de una casa vetusta y apartada. Descubierto por los terroristas, que estaban fabricando bombas, es golpeado y maniatado y dejado librado a su suerte. Después de grandes esfuerzos logra deshacerse de sus ligaduras y llegar hasta la casa de Martín [¿Carlos Duval?], a quien en venganza iban a tirar una bomba aprovechando la ocasión de celebrarse una fiesta. Y su llegada coincide con la de los terroristas; estos tiran la bomba, Lake da la voz de alarma y Sonia recoge la terrible caja destructora y la tira por el balcón afuera, en ese momento explota y mata sin
} 
del anarquista está signada, en primer lugar, por el camuflaje y por un falseamiento de la identidad, no solo de una persona por otra, sino de dos modelos antagónicos de inmigrante: uno propiciado por el Estado, el emprendedor norteamericano, honesto y trabajador, frente al enemigo del orden, el anarquista ruso, "terrorista" y corruptor.

Como ocurría en Alma argentina (1919), el extranjero "malo" estaba asociado por su nacionalidad a la Rusia bolchevique e ideológicamente al anarquismo, la misma conjunción de sectores que según la Liga Patriótica pretendían crear las condiciones para instaurar la "dictadura de los soviets" durante la Semana Trágica. Su carácter de deportado podría relacionarse con los reclamos en favor de los presos políticos y de los deportados durante el Verano Rojo y la Huelga de las Bombas. El film, por el contrario, valida las leyes represivas del Estado de ese período, como la Ley de Residencia, que suponía la expulsión de extranjeros por el mero hecho de participar en huelgas o en protestas sociales. Pero también, en forma implícita, marca sus limitaciones y tal vez la necesidad de una legislación aún más represiva debido a que nuestras fronteras no resultan todavía lo suficientemente inexpugnables.

Por otro lado, uno de los hechos que tuvo una aterrada cobertura periodística fue el hallazgo de material explosivo en manos anarquistas durante "La Huelga de las Bombas". Según el guion de la película, el grupo "terrorista" también planeaba organizar atentados con explosivos ahora en la ciudad, fabricados en una casa vetusta "en un rincón de la provincia de Buenos Aires", posiblemente una zona similar a la del conurbano, como Lanús o Avellaneda, donde la policía realiza los allanamientos más importantes durante "La Huelga de las Bombas".

Además, y esto es un detalle relativamente nuevo, este mal extranjero no queda solamente enquistado en el ámbito cosmopolita de la ciudad, sino que se expande a los alrededores de Buenos Aires e intenta socavar un espacio paradigmático de la Nación: el campo. Es decir, el espacio moralmente puro, pacífico, del trabajo, ligado a la tierra y por lo tanto a nuestras raíces, y ajeno a los males de la ciudad cosmopolita. Hay que tener en cuenta que la Semana Trágica, el Verano Rojo y la Huelga de las Bombas ocurrieron muy cercanos en el tiempo, y el film refleja el marco interpretativo que se les dio a estos hechos en amplios sectores de la prensa: la idea de un complot que se expande de manera incontenible y que es necesario neutralizar urgentemente.

Frente a esa incontenible expansión del mal, la única solución propuesta por este film trasciende todo esquema legalista o toda redención: luego de ser descubierto un complot anarquista gracias al accionar del "buen" inmigrante estadounidense, el deportado ruso termina por ser exterminado con una bomba lanzada en forma involuntaria por un familiar. Una muerte que implica una necesaria purificación social, y posibilita un happy end explícitamente conservador ${ }^{30}$.

saberlo a su propio hermano. Margarita vuelve a su casa y comprende el amor de Casimiro, Duval llega a amar a Sonia y Lake se da cuenta de su error y vuelve a Norte América y sobre todas las cosas triunfa la verdad; el amor, lo único que no muere a través de los tiempos, lo único que construye y lo conserva todo" (Crítica, 28/9/21, 3).

${ }^{30}$ Así termina la sinopsis: “...y sobre todas las cosas triunfa la verdad; el amor, lo único que no muere a través de los tiempos, lo único que construye y lo conserva todo”. Ïbid, subrayado nuestro. 
El triunfo de la verdad, escrita y dirigida por el estadounidense Hugh Perry, conjuga dos visiones conspirativas sobre el anarquismo, ya que por un lado incorpora los estereotipos reaccionarios del cine norteamericano sobre el "terrorismo ácrata", 31 y por otro la mirada atemorizada sobre la expansión de la protesta social que sostenía la elite dominante, precisamente la clase con la que Perry entra en contacto para financiar sus películas. $^{32}$

Después de todo, el recuerdo reciente del "Verano Rojo" y "La Huelga de las Bombas" amenazaba con actualizarse en diversas regiones del país, tanto en el norte, con la "huelga grande" en la Forestal, a fines de enero de 1921, como en el sur, con el triunfo, a mediados de febrero de ese año, de la lucha de los peones de Santa Cruz contra los grandes terratenientes, que había suscitado expropiaciones y ocupación de estancias. ${ }^{33}$

\section{La Patagonia rebelde}

La importancia que adquirió la región patagónica en los medios de prensa debido a las huelgas y los fusilamientos en Santa Cruz (1920-1922) determinó que un productor como Federico Valle, conocedor de la opinión pública como director del semanario documental Film Revista, enviara, en febrero de 1922, una troupe cinematográfica para filmar un documental y tres películas de ficción. Dos de ellas, ;Patagonia! (1922) y Allá en el Sur... (1922), de las cuales pudimos reconstruir el argumento, establecen referencias tangenciales a los conflictos sociales de Santa Cruz. Se trata de obras enmarcadas en el género del melodrama, donde prima el desborde de las pasiones, la dicotomía purezapecado y, en general, la reducción de los conflictos a lo sentimental. En ellas, el sur argentino es representado como el espacio de la naturaleza virgen, de la belleza exótica del paisaje, pero también como el espacio de lo salvaje, de la ausencia de toda institución del Estado, sin el imperio de la ley ni del orden. Es un espacio en alguna medida ajeno al territorio nacional reconocible, es decir un lejano "Allá en el Sur..." habitado por personajes de orígenes "extraños" (indígenas, ingleses o franceses), al cual ingresamos como espectadores a través de personajes femeninos (y por ende representados como "vulnerables") que vienen de otro lugar. En definitiva, un territorio que termina por

\footnotetext{
${ }^{31}$ No casualmente el héroe del film que logra desbaratar la célula terrorista es un estadounidense.

${ }^{32}$ Perry estrenará unos pocos meses después El collar de perlas, protagonizado por miembros de familias aristocráticas, basado en un argumento de Hugo Wast, y exhibido en un festival a beneficio de la Liga Patriótica.

${ }^{33}$ Esa expansión de la conflictividad social protagonizada por sindicatos de tendencia anarquista también se puede observar en los centros urbanos durante esos años, como da cuenta el contenido de los noticiarios cinematográficos de la época. Por ejemplo, el sumario de las Actualidades Tylca (10/4/21) menciona: "2) Conflictos sociales: La bomba de la calle Estados Unidos", referido a un atentado contra la patronal realizado según la prensa por el gremio de panaderos, mientras que el del Film Revista Valle (2/6/21) y de las Actualidades Tylca (28/5/21 y 7/6/21) informan sobre la huelga llevada a cabo por la Unión de Chauffeurs en reacción al asesinato de militantes perpetrado por la Liga Patriótica Argentina.
} 
modelar la psicología de los personajes que lo habitan, ya sea el "buen salvaje”, el lugareño rudo y parco, o seres dominados por el impulso sexual frente a mujeres indefensas y por el goce del poder sin límites.

¡Patagonia! inicia su trama con una familia humilde que "huye de los campos donde los bandoleros de Santa Cruz han saqueado todos los hogares",34. El padre, ya enfermo muere a raíz de la travesía, y sus dos jóvenes hijas quedan a merced de la lascivia de los hombres "rústicos" de la zona. Hay que tener en cuenta que la denominación "bandoleros de Santa Cruz" es característica de la prensa reaccionaria de la época para referirse al segundo movimiento huelguístico de $1921 .{ }^{35}$ De esta manera el film parece vincular a los anarquistas con delincuentes que saquean hogares, atentan contra la propiedad privada y destruyen los patrones legítimos de autoridad (el anciano padre).

Allá en el Sur... narra la historia de Sander, un colono duro y parco, y su esposa, que son acosados por un lascivo usurero. A su morada acude una cuñada, ("una oveja descarriada", como dice una de las sinopsis) que viene de la ciudad, a la que él rechaza por su oscuro pasado. Sin embargo, esta mujer termina sacrificándose, entregándose al usurero para pagar las deudas de la familia. El colono, que impide ese sacrificio matando al usurero, es descripto de la siguiente forma: "Era el obrero 'bueno', el peón 'regenerado' de Sander, ayer exigente por sus jornales $\mathrm{y}$ ahora, acaso por virtud de una mirada $\mathrm{y}$ de un agradecimiento, el salvador oportuno...". 36 En el protagonista ocurrió una conversión: por gracia de la feminidad dejó atrás su carácter tosco, su hostilidad y su intransigencia, su pasado huelguista en definitiva, cuando era demasiado "exigente" con los patrones, para humanizarse y transformarse en un "obrero bueno". De esta forma los conflictos sociales desaparecen -se ocultan- bajo la expresión de nobles sentimientos del folletín, como si después de todo esa tierra agreste y violenta solo necesitara ser fecundada por un amor casi religioso.

En síntesis, el cine de Federico Valle omite toda referencia a la explotación del peón por parte de los grandes terratenientes, determinante en las huelgas patagónicas, para solo aludir a la usura y "perversión" de un simple prestamista. Tampoco establece referencia alguna al fusilamiento de los huelguistas perpetrado por el ejército bajo órdenes del gobierno yrigoyenista, a pesar de que el período de filmación se produce en un territorio recién "pacificado", y en un contexto determinado por las denuncias de la prensa de izquierda y progresista. Por el contrario, la Cinematografía Valle implícitamente valida esa pacificación, la necesidad imperiosa de la instauración del orden civilizado en un territorio bello pero excesivamente "anárquico", ya sea a través de la condena a "los bandoleros de Santa Cruz" que saquean los campos, o con la conversión de los huelguistas en obreros buenos y mansos. Después de todo, la Cinematografía Valle realizó documentales para la

\footnotetext{
${ }^{34}$ La República, 2/10/22, 5.

${ }^{35}$ En realidad, el sindicalismo anarquista solo realizó actos de expropiación y ocupación de algunas grandes estancias, y no de todos los hogares, que incluirían a pequeños propietarios, como parece dar a entender el film. Ajeno al movimiento huelguístico, surgió un pequeño grupo armado que se dedicó al bandidismo, el cual como en el film fue usado por la prensa como símbolo de todo el proceso de protesta. La referencia en ¡Patagonia! a la amenaza hacia la sexualidad de las hijas en un contexto de "los saqueos de los bandoleros" podría remitir a los rumores acerca de violaciones perpetradas por los huelguistas, nunca comprobadas.

36 “Teatro del Silencio”, Caras y Caretas 1249, 9/9/22.
} 
Liga Patriótica y promocionó sus actividades en su semanario Film Revista Valle durante y con posterioridad al período de las huelgas patagónicas. ${ }^{37}$

Esta visión negativa de las luchas sociales propia del cine nacional de la época es puesta en cuestión con el estreno de La ley del hombre (1922), un melodrama de aventuras dirigido por el cineasta italiano Alberto Traversa, y escrito y protagonizado por un joven inmigrante español, León Artola. ${ }^{38}$

La película narra la historia de José Fuentes, un ex obrero que, perseguido por la justicia, halla refugio en una tribu de onas de la Patagonia, de quienes se transformará en cacique. Un indio rival intentará violar a la hermana de un estanciero, pero Fuentes interviene y la salva, iniciándose una historia de amor entre ellos. El estanciero, escandalizado por la relación de su hermana con "un salvaje", la encierra. Pero ella logra escaparse para encontrarse en los brazos de su amante. La intervención del indio rival y de una india enamorada de José hará que todo termine en una gran tragedia.

Más allá de esta sinopsis, que remite a una estructura propia del melodrama, se puede vislumbrar, a partir del relevamiento de otras fuentes de la época, una obra que aborda ciertas problemáticas políticas desde una perspectiva atípica para el cine del período.

En la historia de este obrero perseguido que va a terminar formando parte de una tribu indígena patagónica, La ley del hombre dará cuenta de los dos espacios y acontecimientos característicos del anarquismo y otras tendencias radicalizadas en el cine del periodo: la ciudad, el Buenos Aires durante los hechos de la Semana Trágica, y la Patagonia, hacia donde, según el argumento, se envían rompehuelgas en un contexto que coincide con los sucesos de Santa Cruz.

Por otra parte, por primera vez en el cine, la Semana Trágica es descripta desde el punto de vista del obrero que participa de la huelga. En un flashback se cuenta cómo llegó Fuentes a integrarse a la tribu indígena. Fuentes había sido un obrero que padecía la miseria ya que se había quedado sin trabajo debido a su participación en la huelga general de 1919. Se ve obligado a robar una cartera para comprar medicamentos para su anciana madre enferma, y es detenido por la policía. Sin embargo, logra ser liberado por sus compañeros de huelga y, luego de ocultarse un tiempo, una vez enterado de la muerte de su madre, decide escapar de la ciudad hacia el sur. En el barco se enfrenta con rompehuelgas que se ríen de su madre muerta, se produce un incendio y naufraga. Este segmento de La ley del hombre responde a los tópicos de la literatura y prensa anarquista y de izquierda: el recurso

\footnotetext{
37 Además, es importante destacar que el $n^{\circ} 112$ (9/2/22) de este noticiario da cuenta del arribo a Buenos Aires del teniente coronel Varela, responsable de la matanza de obreros en Santa Cruz, caracterizándolo como una "personalidad" importante, y que el camarógrafo del Film Revista, Alberto Sorianello, recibió como obsequio de parte de Varela, cuando filmaba la campaña del ejército en el sur, un "winchester usado por los revoltosos” (“El primer operador antártico...", La Razón, 6/3/30).

38 Traversa realiza una serie de películas en nuestro país entre 1918 y 1923, entre ellas Los inconscientes (1918), En un día de gloria (1918), En buena ley (1919), La hija de la pampa (1921), La taba de don Nicasio (1921) y, según algunas fuentes, Guiñol porteño (1923). Por su parte, León Artola luego de participar como intérprete en otros films nacionales como Mala yerba (1920) y La baguala (1923) y de realizar el documental Los gallegos en Buenos Aires, se trasladará definitivamente a España donde continuará su carrera cinematográfica como director y guionista. Durante la década de 1930 filmará varias películas durante la República, y morirá en el transcurso de la Guerra Civil Española.
} 
sentimental de la anciana madre enferma; la fractura de la ley como producto de la miseria; la solidaridad de los compañeros huelguistas con un miembro de su clase social y, en oposición, el crumiro como un ser malvado y despreciable. Finalmente, la figura del perseguido que se ve obligado a dejar la civilización por una ley injusta parece guardar relación con la lectura que parte del anarquismo hará de la gauchesca.

Como en la primera parte del Martín Fierro, el espacio de lo "salvaje" surge como esperanza de evasión de un orden civilizado represivo. En La ley del hombre, el sur patagónico se abre como la posibilidad de libertad, y el contacto del protagonista con una reducida tribu de onas supone la participación del hombre blanco en una forma de organización social diferente.

Y es precisamente en esta tribu indígena donde Fuentes va a encontrar, no el tópico racista del salvaje desalmado, sino un orden social diferente, opuesto (pero esta vez de manera positiva) al orden legal, visto como opresión. ${ }^{39}$ En palabras de un airado cronista de la época: "no lo estamos [de acuerdo] en se tome a nuestra metrópoli [...] como símbolo de perversidad por oposición a la ingenuidad primitiva... ¿de quién? De un prófugo y de unos salvajes [...] Filosofía barata, por supuesto, urdida con lugares comunes acerca de las divergencias entre la civilización y la barbarie y entre los burgueses y los obreros; entre los explotadores de nuestras riquezas espontaneas [los estancieros] y el indio vagabundo, inútil para todo lo que no sea la satisfacción limitada del instinto". "Porque es la misma "ley del hombre" blanco la que se pone en cuestión; la película organiza una serie de oposiciones: obrero/policías y rompehuelgas; indios/estancieros, que cuestionan el status legal mismo. Como señala otro cronista, refiriéndose a los indios: "Los que fueron otrora dueños y señores de las inmensas y dilatadas comarcas son ahora tan solo intrusos en los territorios que el blanco ha ocupado merced a las leyes que en su propio interés dictara". ${ }^{41}$ La esencia de la ley es responder a los intereses de los poderosos, en el caso del film, a un estanciero rico caracterizado como egoísta, frío y misántropo, ${ }^{42}$ y perseguir a los pobres obligados a robar para salvar a una madre enferma. Tanto el obrero huelguista como el indígena padecen el imperio de la ley, que los convierte en excluidos. La conjunción del obrero rebelde y el indígena como símbolo de la barbarie, muy común en los sectores reaccionarios, es ahora reutilizada en un sentido positivo.

Estos elementos, propios de "la literatura roja de pacotilla", ${ }^{43}$ sin embargo, se diluyen en el melodrama, donde el amor entre el prófugo de la justicia y la hermana del estanciero termina trágicamente por los celos y la venganza de algunos integrantes de la

\footnotetext{
${ }^{39}$ En varias crónicas de la época se menciona el libro Tierra del Fuego. Los onas (1910) del Dr. Carlos Gallardo (ver, por ejemplo, Ultima Hora, 4/8/21, 5; El Telégrafo, 5/8/21, 6.), por lo cual es muy probable que haya influenciado la visión sobre el indígena en el film. Este autor los describe como unos Hércules bellos y atléticos, orgullosos pero compasivos con los ancianos y solidarios con los hambrientos, que viven con lo indispensable, y que, a pesar de presentar algunos defectos (ser vengativos, celosos, lujuriosos), carecen de los vicios de la civilización (el dinero, el robo, la propiedad privada, el alcohol). Al mismo tiempo, Gallardo establece una mirada negativa del civilizado que les quita los campos donde cazaban y que los condena a la extinción.

${ }^{40}$ El Telégrafo, 19/9/21, 6.

${ }^{41}$ La Unión, 29/9/21, 23.

${ }^{42}$ Idem.

${ }^{43}$ El Telégrafo, 19/9/21, 6.
} 
tribu y los prejuicios sociales del estanciero. En ese final trágico, determinado por la imposibilidad de ser parte de una sociedad utópica, o de encontrar siquiera un lugar en el mundo, ya sea en la civilización o en la "barbarie", tal vez se vislumbre la situación opresiva y en repliegue propia de un hombre de izquierda en la época, determinada en el film por la derrota del proletariado durante la represión de la Semana Trágica y por la amenaza de esos rompehuelgas que viajan hacia el sur. Los fusilamientos de enero de 1922 en la Patagonia, año del estreno del film, corroborarán en todo caso esa presunción.

\section{Conclusiones}

El período mudo, uno de los menos relevados y estudiados de la historia del cine argentino debido a que la casi totalidad de su producción se encuentra perdida, adquiere suma importancia porque coincide con el protagonismo político y cultural del anarquismo. Ese protagonismo se expresó por primera vez en el campo cinematográfico en el contexto previo al Centenario, y muy especialmente entre los años 1918 y 1922, debido, principalmente a dos factores. En primer lugar, el anarquismo adquirió protagonismo a partir, como señala Doeswijk (2013), a partir del recrudecimiento del conflicto obrero en esos años. En segundo lugar, la producción cinematográfica argentina había alcanzado un desarrollo inusitado en relación a la primera década del siglo $\mathrm{XX}$, cuando el anarquismo tenía una mayor presencia social.

En general, el movimiento libertario asume en la cinematografía nacional de la época un carácter negativo, ya sea desde posiciones más reaccionarias que lo asocian a la barbarie y a lo extranjero como factores amenazantes del orden social, o bien desde posturas más reformistas que parecen aludir al anarquismo a través de la visión un sindicalismo radicalizado que pone en peligro la conciliación de clases. La excepción la constituye La ley del hombre, un film que da cuenta de la solidaridad obrera y de la injusticia social en el marco de las huelgas de enero de 1919.

La desaparición de esta ideología política en el cine de ficción ${ }^{44}$ coincide con un declive de su protagonismo social desde la segunda mitad de la década de 1920. Recién en 1940 el cine nacional retomará la temática con el film Con el dedo en el gatillo (Moglia Bahrt), una visión retrospectiva en clave policial de la vida de Severino Di Giovanni. De ahí en más, el anarquismo en nuestro cine pasará a ser siempre un acontecimiento del pasado histórico, pero que sin embargo se puede reactualizar, una y otra vez, ya sea como símbolo de una amenaza para el orden social, o como un antecedente o referente para un cambio social en Argentina.

\footnotetext{
${ }^{44}$ El anarquismo aparecerá mencionado en algunos noticiarios cinematográficos de fines de la década de 1920 y principios de 1930 (Actualidades Glücksmann, Film Revista y Rapid Film), sobre todo raíz de las acciones emprendidas por los anarquistas expropiadores.
} 


\section{Bibliografía}

Publicaciones periódicas consultadas:

Diarios:

Crítica (Buenos Aires, 1915-1928)

La Mañana (Buenos Aires, 1914-1920)

La Nación (Buenos Aires, 1914-1929)

El Nacional (Buenos Aires, 1909)

El País (Buenos Aires, 1909)

El Pueblo (Buenos Aires, 1914-1929)

La Razón (Buenos Aires, 1914-1931)

La República (Buenos Aires, 1919-1924)

El Telégrafo (Buenos Aires, 1921-1925)

Tribuna (Buenos Aires, 1909)

Última Hora (Buenos Aires, 1920-1932)

La Unión (Buenos Aires, 1915-1923)

Revistas:

Caras y Caretas (Buenos Aires, 1914-1923)

Cine Universal (Buenos Aires, 1919-1921)

Cinema Star (Rosario, 1921-1922)

Excelsior (Buenos Aires, 1914-1932)

Film (Buenos Aires, 1932)

Fray Mocho (Buenos Aires, 1914-1918)

El Hogar (Buenos Aires, 1916-1929)

Imparcial Film (Buenos Aires, 1918-1932)

Mundo Argentino (Buenos Aires, 1917-1919)

PBT (Buenos Aires, 1916-1918)

La Película (Buenos Aires, 1916-1933)

Plus Ultra (Buenos Aires, 1919-1922)

Revista del Exhibidor (Buenos Aires, 1926-1932)

\section{Libros y artículos:}

- Acosta, José, "Estadística aduanera", Excelsior 200, Buenos Aires, 1/1/18, 84.

- Anuarios estadísticos de la ciudad de Buenos Aires: 1891-1923, Buenos Aires, Dirección General de Estadísticas y Censos / Gobierno de la Ciudad Autónoma de Buenos Aires, 2010.

- Ascolani, A., "Una ciudadanía restringida, tensiones en torno a los derechos y las obligaciones del magisterio. La gran huelga de 1921, Santa Fe, Argentina", Educação em foco $15,2011$.

- Bayer, Osvaldo, La Patagonia rebelde. Tomo I y II, Buenos Aires, La Página, 2009. 
- Bernini, Emilio, "Escenas callejeras. La ciudad en el cine argentino 1919-1943”, El Matadero 2, Buenos Aires, Facultad de Filosofía y Letras, 2000.

- Bilsky, Edgardo, La semana trágica, Buenos Aires, CEAL, 1984.

- Caneto [et al.], Historia de los primeros años del cine en la Argentina. 1895-1910, Buenos Aires, Fundación Cinemateca Argentina, 1996.

- Centro de Investigación de la Historia del Cine Argentino (CIHCA), La época muda del cine argentino (reseña biográfica), Buenos Aires, Cinemateca Argentina, 1958.

- Couselo, Jorge Miguel, "El período mudo", en Historia del cine argentino, Buenos Aires, Centro Editor de América Latina, 1992.

- Di Núbila, Domingo, Cuando el cine fue aventura. El pionero Federico Valle, Buenos Aires, Ediciones del Jilguero, 1996.

- Di Núbila, Domingo, La época de oro del cine argentino, Buenos Aires, Ediciones del Jilguero, 1998.

- Doeswijk, Andreas, Los anarco-bolcheviques rioplatenses (1917-1930), Buenos Aires, CeDInCI, 2013.

- Gallardo, Carlos, Tierra del Fuego. Los Onas, Buenos Aires, Cabaut y Cía, 1910.

- Godio, Julio, La Semana Trágica de enero de 1919, Buenos Aires, Granica editor, 1972.

- González López, Palmira - Cánovas Belchi, Joaquín, Catálogo del cine español. Volumen

F 2. Las películas de ficción (1921-1930), Madrid, Filmoteca Española, 1993.

- Gori, Gastón, La Forestal. La tragedia del quebracho colorado, Buenos Aires, Proyección, 1974.

- Jasinski, A., Revuelta obrera y masacre en La Forestal, Buenos Aires, Biblos, 2013.

- Kohen, Héctor, “Algunas bodas y muchos funerales", Cuadernos de Cine 5, Buenos Aires, 2005.

- Lecuona, Juan Benito, El triunfo de la verdad, Buenos Aires, Nocito \& Rañó, [1921].

- López Arango - Emilio y Abad de Santillán, Diego, El anarquismo en el movimiento obrero, Barcelona, Cosmos, 1925.

- Lusnich, Ana Laura - Piedras, Pablo (edit.), Una historia del cine político y social en Argentina (1896-1969), Buenos Aires, Nueva Librería, 2009.

- Lvovich, Daniel, "La Semana Trágica en clave transnacional. Influencias, repercusiones y circulaciones entre Argentina, Brasil, Chile y Uruguay (1918-1919)", en Circule por la derecha: percepciones, redes y contactos entre las derechas sudamericanas, 1917-1973, Los Polvorines, Universidad Nacional de General Sarmiento, 2016.

- Mafud, Julio, La vida obrera en la Argentina, Buenos Aires, Proyección, 1976.

- Mafud, Julio, Contenido social del Martín Fierro, Buenos Aires, Distal, 1986.

- Mafud, Lucio, La imagen ausente: El cine mudo en publicaciones gráficas. Catálogo. El cine de ficción (1914-1923), Buenos Aires, Biblioteca Nacional /Teseo, 2016.

- Manrupe, Rául - Portela, María Alejandra, Un diccionario de films argentinos (1930-1995), Buenos Aires, Corregidor, 2005.

- Maranghello, César, Breve historia del cine argentino, Barcelona, Laertes, 2005.

- Marrone, Irene, Imágenes del mundo histórico. Identidades y representaciones en el noticiero y el documental en el cine mudo argentino, Buenos Aires, Biblos / Archivo General de la Nación, 2003.

- Oger, Adriana y Daniel de Lucia, " $¡ N i$ dios, ni amo, ni taquilla! El anarquismo en el cine argentino", Pacarina del Sur 11, abril-junio, 2012. 
- Pérez, Pablo M. [et. al.], Catálogo de publicaciones políticas, sociales y culturales anarquistas (1890-1945), Buenos Aires, Federación Libertaria Argentina/ BAEL/Reconstruir, 2002.

- Pittaluga, Roberto, Soviets en Buenos Aires, Buenos Aires, Prometeo, 2015.

- Rey, Ana Lía, Periodismo y cultura anarquista en la Argentina de comienzos del siglo XX: Alberto Ghiraldo en "La Protesta" y "Martín Fierro", Buenos Aires, Hipótesis y Discusiones 24, Facultad de Filosofía y Letras/ Universidad de Buenos Aires, 2004.

- Ruiz, Luis Enrique, El cine mudo español en sus películas, Bilbao, Mensajero, 2004.

- Suriano, Juan, "El anarquismo", en Nueva historia argentina. Tomo V. El progreso, la modernización y sus límites (1880-1916), Barcelona, Sudamericana, 2000.

- Talents, Jenaro - Zunzunegui, Santos (coord.), Historia general del cine. Volumen IV: América (1915-1928), Madrid, Cátedra, 1997.

- Talents, Jenaro - Zunzunegui, Santos (coords), Historia general del cine. Volumen III: Europa 1908-1918, Madrid, Cátedra, 1998. 